I Universidade Federal de Santa Maria (UFSM), Programa de Pós-Graduação em

Comunicação, Santa Maria, RS, Brasil

sandraxrubia@gmail.com

https://orcid.org/oooo-000I-7548-5178

I I Universidade Federal de Santa Catarina (UFSC), Departamento de Jornalismo,

Florianópolis, SC, Brasil

machado.alim@gmail.com

https://orcid.org/oooo-0003-1687-7248

Sandra Rúbia da Silva'

Alisson Machado"

\title{
DIÁLOGOS COM DANIEL MILLER NO CAMPO DA COMUNICAÇÃO: REFLEXÕES A PARTIR DAS PESQUISAS DO GP CONSUMO E CULTURAS DIGITAIS
}

A antropologia, cuja base é o trabalho etnográfico, renova sua tradição a partir dos conhecimentos adquiridos em sua história disciplinar quando confrontados com as observações realizadas a cada vez que novos(as) pesquisadores(as) vão a campo (Peirano, I994; Cardoso de Oliveira, 2006). Esses saberes atualizam o ethos antropológico e orientam as interpretações não apenas por servir como teoria, mas porque sinalizam, alertam e inspiram reflexões referentes à objetividade relativa que caracteriza a natureza do entendimento antropológico (Geertz, 20I3; Velho, 20I3). Se, por um lado, o texto representa a materialização e a reinscrição comprometida do(a) pesquisador(a) (Clifford, I998; Strathern, 20I4), por outro, existe um trabalho constitutivo da imaginação antropológica que se produz no espaço entre, entre texto e experiência, que desloca os eixos entre o "estar lá" e o "estar aqui", resultado desse tipo de empenho interpretativo (Geertz, 20I2).

Esse entre pode ser vivenciado de diferentes formas, entre elas pelos entrecruzamentos das fronteiras disciplinares. Tendo em vista a articulação desse lugar de interfaces, o objetivo do artigo é, ao examinar dez pesquisas realizadas pelo Grupo de Pesquisa Consumo e Culturas Digitais (UFSM/CNPq), discutir como o legado teórico e metodológico de Daniel Miller tem sido incorporado nesse conjunto de reflexões, reconhecendo a potência do método etnográfico para a análise cultural e para a descrição da cultura digital e dos ambientes de interação online. 
Nossas práticas assumem a comunicação como um campo transdisciplinar (França, 200I; Martín-Barbero, 2009) também demarcado pelo que Grossi (2004) chamou de parentesco acadêmico: as filiações teóricas e relações sociais estabelecidas pelo e no processo de orientação, o que pode ser entendido principalmente pelas heranças recebidas dos(as) orientadores(as) que funcionam nos moldes dos regimes das reciprocidades (Mauss, 2003). Conhecimento recebido e presentificado nas experiências de cada trabalho de campo. Hau adquirido, levado consigo e sempre adiante.

O GP aproximou estudantes - principalmente da área da comunicação - da antropologia, apresentando, discutindo e produzindo um fazer etnográfico com nuanças próprias da pesquisa em comunicação, mobilizado por questõesproblema que envolvem o enfrentamento das mídias e das tecnologias digitais na vida cotidiana e as distintas mediações com as instâncias sociotécnicas que conformam as culturas midiáticas. ${ }^{2}$ Esse encontro resultou no investimento de vivências propriamente antropológicas (DaMatta, 20I0) e na busca de formulações teórico-etnográficas (Peirano, 20I4) para a compreensão dos artefatos das culturas digitais e das diferentes apropriações e usos ${ }^{3}$ que os atores sociais fazem dessas tecnologias.

Somos todos(as) herdeiros(as), por um lado, da tradição fonsequiana de "fé no trabalho de campo" (Brites \& Motta, 20I7), pois, no doutorado em antropologia social na Universidade Federal de Santa Catarina (2006-20Io), Sandra Rúbia, líder do GP, foi orientanda de Carmen Silvia Rial, que fora orientanda de Claudia Fonseca. Durante o doutoramento, Sandra ainda realizou um período de estágio doutoral na University College London, sob orientação de Daniel Miller.

A obra de Miller e coautores(as) provou ter influência duradoura na futura tese, tanto em termos teóricos quanto metodológicos, influência essa que persistiu posteriormente nos trabalhos orientados por Sandra Rúbia. Como legado temos, de um lado, a revelação da potência de uma antropologia da comunicação para a compreensão do papel das tecnologias móveis e da internet na cultura e nas relações sociais, bem como no consumo como cultura material (Horst \& Miller, 2006) e, de outro, a reflexão sobre a obra seminal de Christine Hine (2000), Virtual ethnography. Desse livro, revelaram-se fundamentais tanto o entendimento da internet como um artefato cultural quanto a crítica à dicotomia online e off-line presente nos primeiros estudos sobre a internet, crítica essa empreendida em diálogo com Miller e Slater (2000) e posteriormente aprofundada na compreensão da internet como dimensão incorporada, corporificada e cotidiana (Hine, 20I5).

As pesquisas do GP buscam construir diálogos com importantes trabalhos, como os advindos da atuação de Livia Barbosa, principalmente sobre as relações entre consumo e cultura material (Barbosa, 2003; Barbosa \& Gomes, 2004; Barbosa \& Campbell, 2006) e de Carla Barros (2007), em relação às mediações cul- 
turais pelo consumo e à perspectiva etnográfica para a investigação midiática (Campanella \& Barros, 20I6). Além de fomentar o campo e traduzir importantes textos sobre consumo, Livia Barbosa foi responsável pela visita de Daniel Miller ao Brasil em 2006. A respeito dos estudos da cultura material, é possível pontuar pesquisas sobre a circulação de mercadorias e pessoas (Pinheiro-Machado, 2009; Martineli, 20I I) e sobre relações entre consumo, formulações identitárias e culturais (Machado, 20I0; Mizrahi, 20I4). Além dessas, constituem uma mira$\mathrm{da}$ aos estudos da antropologia do consumo a perspectiva comparada entre Brasil e Argentina (Leitão et al., 2006) e a 28ª edição da revista Horizontes Antropológicos, em comemoração à publicação do livro 0 mundo dos bens, de Mary Douglas (Oliven \& Pinheiro-Machado, 2007).

Os enfoques interpretativos das pesquisas analisadas aglutinam esforços em compreender as apropriações de sites e aplicativos digitais, bem como smartphones e computadores nas periferias urbanas, por grupos populares, em vulnerabilidade, subalternidade social ou desprovidos de poder institucional. ${ }^{4} \mathrm{~A}$ pluralidade que demarca esses distintos contextos de pesquisa permite o desenvolvimento de práticas etnográficas em espaços sociais diversos reconfigurados pelas tecnologias de comunicação digital (Horst et al., 20I2). A etnografia, como uma prática de pesquisa interdisciplinar, é ela própria adaptável a diversos campos, ambientes e situações, refletindo a pluralidade das relações humanas sejam elas consideradas em formatos mais tradicionais de interação ou aqueles característicos das culturas digitais. Miller, em entrevista a Monica Machado (20I5), afirma:

em nossos estudos, descobrimos que a comunicação digital frequentemente ainda tem base nas unidades dos estudos da antropologia mais tradicional. Assim, em nosso estudo na Índia, mostramos que a casta é central na forma como a rede social é usada, enquanto nos estudos na Turquia ela é mais tribal e, em outros estudos, tem mais base na família. Todos esses estudos antropológicos ligam o individual ao social em vez de vê-los como duas categorias opostas na vida.

As pesquisas analisadas buscaram construir costuras interdisciplinares (Fonseca, I999) considerando os contextos e as materialidades das interações digitais, bem como os desafios de repensar a extensão da etnografia nas mídias como ambiente, objeto e instrumento de pesquisa (Sheppard, 20I2). Essa perspectiva entende que os artefatos digitais participam ativamente da cultura material e que a internet pode ser mais bem compreendida não como um aparato técnico em si, mas como uma tecnologia social e dinâmica que habilita as pessoas a criar outras tecnologias sociais (Miller, 2007, 20I3; Miller et al., 2016). É na atenção dedicada aos diferentes contextos que as práticas na internet, em sua dimensão plural, podem ser reconhecidas, pois

deixamos de pensar em tecnologias da comunicação como coisas, ou capacidades, e começamos a vê-las como análogas à arte da sedução: modos de nos fazer 
atraentes para a pessoa com quem nos comunicamos. Claro, a sedução é apenas uma das muitas coisas que estão em jogo aqui. A questão mais ampla é que as tecnologias da comunicação são essencialmente gêneros culturais, e que a melhor maneira de apreciá-las é comparável à que usamos para outros gêneros culturais (Miller, 2013: I70).

Pensar esses gêneros culturais na perspectiva dos estudos da cultura material (Miller, I987) permite perceber o processo dialético entre os bens materiais (neste caso, as mídias e tecnologias digitais) e os gêneros culturais utilizados para criar, manter, estabelecer, reforçar ou mesmo romper as relações sociais. Ao mesmo tempo, imersas nas particularidades de suas culturas, as pessoas criam formas de relacionamento umas com as outras e, com isso, formas de se relacionar com as mídias. Nesse processo, participam também as formatações e determinações tecnológicas que constituem esses ambientes e que impactam as inteligibilidades sociais.

Nesses cenários, o(a) pesquisador(a) se insere nas redes que constituem as interações, podendo desenvolver para cada ambiente que percorre uma sensibilidade etnográfica que melhor permita compreender os fluxos e as dinâmicas das interações em cada contexto (Leitão \& Gomes, 20I7). Isso implica diálogo com outras fontes de pesquisa, perseguindo questionamentos a respeito de como a internet se caracteriza para um determinado grupo e das circunstâncias em que as conexões ocorrem (Hine, 2015). Além disso, investem na imersão em um campo particular de interlocutores(as), cujas reflexões são conduzidas pelas principais técnicas do trabalho etnográfico, como a observação participante e manutenção do diário de campo (Miller \& Slater, 2000).

As seis dissertações e quatro teses analisadas neste artigo contemplam contextos sociais específicos que se estabelecem nas apropriações das tecnologias digitais e mídias sociais na vida cotidiana, singularizadas por elementos como gênero, sexualidade, geração, agremiações, trabalho, condições socioeconômicas, posições políticas e religiosas e demais elementos que constituem, de forma conjunta e interconectada, as experiências vividas na internet.

\section{DEZ CONTEXTOS DE PESQUISA EM MÍDIAS DIGITAIS}

Para a análise, desenvolvemos um protocolo analítico de pesquisa bibliográfica (Salvador, I986; Gil, I999). Ocupamo-nos, neste momento, em apresentar brevemente cada uma delas. A partir disso, apresentamos inferências teóricas que têm por objetivo perceber como as pesquisas dialogam com noções advindas da antropologia digital. Dessa forma, identificamos como algumas das proposições de Miller são incorporadas em nossas reflexões, seja na dimensão da vivência do trabalho de campo ou da interpretação das apropriações e usos descritos.

A dissertação de Tondo (20I6) investigou o consumo de smartphones entre jovens moradores de uma comunidade popular na cidade de Santa Maria 
(Rio Grande do Sul). A aproximação com o campo ocorreu pela promoção de uma atividade socioeducativa, com duração de um ano letivo, com 43 jovens de uma escola. A partir disso, o autor passou a conviver com quatro jovens de três famílias, buscando entender a importância desse dispositivo nas dinâmicas de posse e consumo das mídias digitais e as formas como o relacionamento dos(as) jovens entre si e com seus familiares era organizado.

Em sua dissertação, Pereira (2017) realizou um estudo com duração de I 2 meses sobre o consumo de smartphones por sete mulheres cisgêneras de camadas populares, de diferentes faixas etárias e bairros de Santa Maria. A autora atentou para as interfaces entre a produção/reprodução das demarcações de gênero e as tecnologias digitais, percebendo que o gênero constitui uma especificidade do consumo dos celulares. Por meio desses aparelhos, as interlocutoras se mantinham como trabalhadoras autônomas e interpretavam a si mesmas, construindo modelos de feminilidade, sexualidade, maternidade, as sim como suas relações amorosas e familiares.

A tese de Menezes (20I7) analisou os deslocamentos dos fluxos midiáticos e estéticos realizados por dançarinos(as) do grupo cultural-identitário Dream Team do Passinho. Mediante a comparação entre o discurso do grupo nas redes sociais e os discursos das mídias tradicionais, a autora interpretou os usos das linguagens televisuais, principalmente da informal, utilizada com o intuito de aproximação ao cotidiano das favelas cariocas.

Kuntz (20I8) tratou em sua dissertação da participação das crianças no contexto de produção de conteúdo, tendo o objetivo de compreender como utilizavam o YouTube para expressão, sociabilidade e aperfeiçoamento pessoal e como essa plataforma incidiu sobre a infância e a maternidade/paternidade. A autora triangula estudos de casos empíricos de crianças que estão à frente de canais com grande número de seguidores com as experiências e interações que realizou durante 8 meses de pesquisa com quatro youtubers mirins iniciantes.

A dissertação de Trindade (2018) identificou os circuitos em que ocorrem a construção e a manutenção da sociabilidade juvenil por meio das práticas de consumo de smartphones de um grupo de I3 jovens do ensino médio em duas escolas de Santa Maria durante o período de I5 meses. O autor encarou as apropriações desses artefatos como uma via de acesso à internet que organizava as redes de relacionamento e os modos como a privacidade era construída e mantida nessas relações.

A tese de França (20I8) investigou a participação política na internet, percebendo as redes sociais digitais como uma arena informal para as discussões de cinco SUGs (sugestões legislativas) apresentadas no e-Cidadania, portal do Senado Federal. A autora buscou perceber as apropriações que atores políticos e cidadãos faziam da internet, especialmente na promoção de debates para o agendamento midiático dos temas sugeridos a fim de que eles interferissem nas pautas do Senado. 
Flores da Rosa (20I8) apresenta em sua tese um estudo sobre a atuação do leigo na internet para pensar a inserção dessas pessoas na produção e consumo de conteúdo religioso. O objeto empírico foi o blog "O Catequista", criado para tratar de assuntos doutrinários e temas diversos a partir de uma visada de reinstitucionalização católica pela atuação na mídia, pelo conservadorismo e pela oposição a ideias marxistas/socialistas/comunistas. O trabalho de campo foi realizado a partir da observação participante, entrevistas e visitas aos blogueiros no Rio de Janeiro, entre 2014 e 20I8, e com seis leitores, de 2017 a 2018.

Em sua dissertação, Paz (2019) buscou compreender o consumo das redes sociais digitais por jovens em torno da temática das ideações suicidas. Por imersão etnográfica durante o período de I 2 meses, foram observadas as práticas desenvolvidas no "Grupo Suicidas", grupo fechado no Facebook, e na "Comunidade Kaneki”, organização formada por jovens que, entre outras ações, promovem práticas voluntárias, colaborativas e solidárias para o combate ao suicídio no Brasil.

A dissertação de Pavanello (20I9) teve como problemática compreender as práticas de consumo das redes sociais por quatro mães de vítimas do incêndio da Boate Kiss, ocorrido em janeiro de 2013, em Santa Maria. A autora atentou para a criação de experiências digitais no cotidiano pós-tragédia das mães, percebendo nos usos das mídias digitais formas de reestruturar a vida após o acontecimento. O trabalho de campo teve duração de I 2 meses, assumido pelas dinâmicas ativistas das mães em sua luta por justiça.

Por fim, a tese de Machado (20I9) apresenta um estudo sobre as apropriações das mídias digitais na formulação do cotidiano de interlocutoras travestis, a maioria delas profissionais do sexo. O trabalho de campo teve duração de três anos e foi realizado em regimes de curta e longa duração, dependendo das "temporadas" das interlocutoras, que mantinham um fluxo de viagens em razão do trabalho. Os contextos de interação observados são demarcados pela precariedade social e por distintas manifestações da violência.

o quadro a seguir organiza uma apresentação por título, autoria, ano de defesa e principais gêneros culturais observados. Essa ênfase foi motivada, a partir da perspectiva da antropologia de Miller, por meio dos principais achados empíricos, compreendendo práticas, tendências, continuidades e rupturas nas dinâmicas e experiências sociais descortinadas no trabalho etnográfico e singularizadas pelos usos e apropriações das tecnologias digitais em cada contexto de pesquisa. 
Quadro I

Principais gêneros culturais observados nas pesquisas

Fonte: elaborado pelos autores.

\begin{tabular}{|c|c|}
\hline Título (autoria, ano) & Principais gêneros culturais \\
\hline $\begin{array}{l}\text { Celulares, conexões e afetos: a sociabilidade } \\
\text { e o consumo de smartphones entre jovens } \\
\text { de comunidade popular (Tondo, 20I6) }\end{array}$ & $\begin{array}{l}\text { Dispositivo como mediador de afetos e performances } \\
\text { Dificuldades geracionais de letramento digital } \\
\text { Não tornam públicas desavenças entre familiares e } \\
\text { amigos(as) } \\
\text { Racionalização pouco efetiva por parte de pais e mães } \\
\text { Satisfação familiar de oferecer acesso à internet } \\
\text { Na internet, os(as) filhos(as) estão em casa: pais/mães } \\
\text { sentem que ofertam proteção } \\
\text { Frustação das expectativas amorosas }\end{array}$ \\
\hline $\begin{array}{l}\text { "Em um relacionamento sério com o celular": } \\
\text { uma etnografia das práticas de consumo de } \\
\text { smartphones por mulheres (Pereira, 20I7) }\end{array}$ & $\begin{array}{l}\text { O smartphone significa a internet, e o Facebook, o navegador } \\
\text { Maternidade e status de relacionamento são definidores dos } \\
\text { tipos de publicações } \\
\text { Sem o smartphone não há trabalho } \\
24 \text { horas conectadas com o mundo doméstico } \\
\text { Papéis de gênero normativos: ciúmes como principal motivo } \\
\text { de interdição de alguns tipos de publicações } \\
\text { Uma boa mãe e mulher é reconhecida pelo que publica } \\
\text { É preciso desligar o aparelho para dar conta das atividades } \\
\text { domésticas e familiares }\end{array}$ \\
\hline $\begin{array}{l}\text { No ritmo do passinho: deslocamentos } \\
\text { midiáticos e estetização cotidiana do grupo } \\
\text { Dream Team do Passinho (Menezes, 20I7) }\end{array}$ & $\begin{array}{l}\text { Estratégias visuais consolidadas nas redes para adentrar as } \\
\text { coberturas e a grade da televisão } \\
\text { Demarcação de identidades coletivas por meio de conteúdos } \\
\text { de dança e militância } \\
\text { Deslocamentos do que é ser celebridade na favela } \\
\text { Influência dos patrocinadores nas composições estéticas } \\
\text { Produção de conteúdo digital sem a chancela da gravadora }\end{array}$ \\
\hline $\begin{array}{l}\text { Crianças no YouTube: um estudo } \\
\text { etnográfico sobre as infâncias e suas } \\
\text { estratégias de relacionamento nas mídias } \\
\text { digitais (Kuntz, 20I8) }\end{array}$ & $\begin{array}{l}\text { YouTube como aprendizado de habilidades e expansão da } \\
\text { sociabilidade infantil } \\
\text { Insultos e haters causam insegurança em pais e mães frente } \\
\text { ao retorno financeiro } \\
\text { Imitação de canais famosos: repetição de um modelo de } \\
\text { infância } \\
\text { Fortalecimento de laços com familiares } \\
\text { Papéis projetivos de si (dos pais e das mães) na estética dos } \\
\text { vídeos }\end{array}$ \\
\hline
\end{tabular}




\begin{tabular}{|c|c|}
\hline Título (autoria, ano) & Principais gêneros culturais \\
\hline $\begin{array}{l}\text { "A gente se ama e se odeia ao mesmo } \\
\text { tempo": uma etnografia do consumo de } \\
\text { smartphones em circuitos de sociabilidade } \\
\text { de jovens de camadas populares } \\
\text { (Trindade, 20I8) }\end{array}$ & $\begin{array}{l}\text { Valores da masculinidade hegemônica para ambos os sexos } \\
\text { Imperativo do conflito que admite o cômico } \\
\text { Materialização das disputas (emojis, gifs, memes) } \\
\text { Espaços off-line para liberação do estresse online } \\
\text { Geolocalização e check-ins como forma de usufruir a cidade } \\
\text { Procura de um namoro ideal igual ao do mundo digital } \\
\text { Sentimento frustrado de liberação sexual das jovens em } \\
\text { cenários de machismo } \\
\text { Moralização das estéticas }\end{array}$ \\
\hline $\begin{array}{l}\text { Participação política na timeline: o } \\
\text { Facebook como arena pública para } \\
\text { sugestões legislativas apresentadas no } \\
\text { E-cidadania (França, 20I8) }\end{array}$ & $\begin{array}{l}\text { Apoio às SUGs para movimentar a agenda pública do tema } \\
\text { pleiteante } \\
\text { Cidadão produtor e responsável pela circulação do tema } \\
\text { Mobilização junto a ativistas, blogueiros(as) e youtubers } \\
\text { Atuação individual de cidadãos/ativistas } \\
\text { Superficialidade nas interações devido à matriz interacional } \\
\text { das plataformas }\end{array}$ \\
\hline $\begin{array}{l}\text { A internet dos leigos: catolicismo midiático } \\
\text { e práticas de consumo como experiência } \\
\text { vivida (Flores da Rosa, 20I8) }\end{array}$ & $\begin{array}{l}\text { Tendência ao entretenimento, humor e à catequese de } \\
\text { boteco } \\
\text { Tensões políticas, doutrinárias e litúrgicas entre diferentes } \\
\text { setores da Igreja } \\
\text { Embate digital contra os hereges } \\
\text { Ênfase dada não ao transcendente, mas à vida prática da fé } \\
\text { Mídia como o encontro com a Igreja e suas exigências } \\
\text { Experiências digitais de afirmação da catolicidade: buscam } \\
\text { atingir quem já é católico } \\
\text { Explicação da fé canônica e de temas considerados } \\
\text { polêmicos } \\
\text { Postagens blindadas pelos poderes eclesiais }\end{array}$ \\
\hline
\end{tabular}




\begin{tabular}{|c|c|}
\hline Título (autoria, ano) & Principais gêneros culturais \\
\hline $\begin{array}{l}\text { O suicídio em torno da vida e da morte: } \\
\text { uma etnografia do consumo do Facebook } \\
\text { por jovens (Paz, 2019) }\end{array}$ & $\begin{array}{l}\text { Criação de espaços de escuta } \\
\text { Ações de responsabilidade, cuidado e meios de sustentação } \\
\text { da vida } \\
\text { Interferir pontualmente nos momentos de crise do(a) } \\
\text { suicidando(a) } \\
\text { Maior segurança no desabafo: liberdade em falar da } \\
\text { temática sem ser estigmatizados(as) } \\
\text { Combater a exposição de material íntimo de meninas na } \\
\text { internet por meninos } \\
\text { Tribunais públicos para punição desses acusados } \\
\text { Uso de vários perfis por uma mesma pessoa por se sentir } \\
\text { mais livre para autoexpressão }\end{array}$ \\
\hline $\begin{array}{l}\text { Práticas de consumo das redes sociais } \\
\text { por mães de vítimas do incêndio da Boate } \\
\text { Kiss: a criação de experiências no cotidiano } \\
\text { (Pavanello, 20I9) }\end{array}$ & $\begin{array}{l}\text { Luta por justiça e memória no Facebook } \\
\text { Direito à saudade como demarcação política em um cenário } \\
\text { marcado pela impunidade } \\
\text { Narrativas para corporificar nos outros a dor que sentem } \\
\text { Proteção afetiva e recurso terapêutico } \\
\text { Sentem-se mais protegidas de insultos em seus perfis do } \\
\text { que na Tenda da Vigília (local de memória mantido pelos } \\
\text { familiares das vítimas) } \\
\text { Facebook para manter diálogos com os(as) filhos(as) } \\
\text { mortos(as) } \\
\text { Manutenção dos perfis da mesma forma como outros } \\
\text { objetos significativos são preservados } \\
\text { A mediação tecnológica diminui as distâncias insuperáveis }\end{array}$ \\
\hline $\begin{array}{l}\text { Toda trabalhada na wi-fi: cotidiano travesti } \\
\text { em trajetórias digitais (Machado, 20I9) }\end{array}$ & $\begin{array}{l}\text { Manutenção de reputações pela valorização da honestidade } \\
\text { Fofocas e jocosidade para demarcar a fidelidade a si } \\
\text { mesmas } \\
\text { Sentem que não têm direito à privacidade } \\
\text { No trottoir também se busca conexão wi-fi } \\
\text { Fazer a pista conectada é menos arriscado } \\
\text { Dinâmicas da prostituição contidas nos celulares: } 24 \text { horas } \\
\text { conectadas para o sexo (cansaço e diminuição da libido) } \\
\text { Trabalho constante de atiçar o desejo das mariconas } \\
\text { O encontro online precisa acontecer off-line para assegurar o } \\
\text { retorno financeiro } \\
\text { O perfil e as publicações são dedicados aos orixás }\end{array}$ \\
\hline
\end{tabular}




\section{OBSERVANDO E REFLETINDO SOBRE OS GÊNEROS CULTURAIS}

Os estudos da cultura material entendem que o consumo dos bens fala sobre e por nós, e que os objetos participam ativamente das elaborações sociais e culturais dos indivíduos e das populações. As pesquisas das culturas digitais permitem compreender os deslocamentos entre o real e o virtual, o material e o imaterial e o online e o off-line como esferas intercambiantes e constituintes das práticas humanas (Horst \& Miller, 20I2). Assim, a pesquisa etnográfica, ao dar ênfase às elaborações cotidianas do uso da internet e dos artefatos digitais, desloca o eixo analítico não para as imposições tecnológicas da cultura, mas para as realizações humanas que definem e dão os contornos de como as mídias são utilizadas.

Os diálogos com Miller apresentados por Silva (2010) em sua tese de doutorado sobre o consumo de telefones celulares em um bairro popular de Florianópolis foram importantes tanto por revelar e avaliar as relações pessoa/telefone - posteriormente desdobradas nas pesquisas de seus(suas) orientandos(as) - quanto por veicular importantes noções teóricas e metodológicas da antropologia das mídias e, especificamente, da antropologia digital. Recebe especial destaque The cell phone: an anthropology of communication (Horst \& Miller, 2006), estudo pioneiro da abordagem etnográfica para a pesquisa sobre telefones celulares.

Em seu estudo, Tondo (20I6) admite que os afetos dos(as) jovens não se relacionavam apenas aos conteúdos das postagens e compartilhamentos nas redes sociais, mas também eram produzidos pela materialidade de controle e posse dos celulares. Os aparelhos desencadeavam emoções específicas - como raiva, quando travavam por pouca memória; inveja, de modelos mais novos e eficientes; felicidade e sentimento de completude, ao encontrar o aparelho que estava perdido. Trindade (2018) percebeu que as performances de ouvir música alta sem fones de ouvidos, nas ruas e nos ônibus, descritas em Silva (2012a), convergiam para os ambientes digitais por meio de novas performances que expandiam os significados da masculinidade nas redes sociais e aplicativos. Da mesma forma, Pereira (20I7) refutou a ideia de que o mundo doméstico seria um mundo atrasado por ser considerado "menos tecnológico" ou "menos mediado" e percebeu como a produção visual, principalmente o compartilhamento de fotografias em formato selfie, atualizava as normatividades de gênero enfrentadas pelas interlocutoras, sobretudo em função das atribuições sociais estabelecidas para homens e mulheres no matrimônio e no sistema de heranças ameaçado na hipótese de separação (Silva, 20I2b).

A leitura de Tales from Facebook (Miller, 20I I), especialmente as I5 teses sobre essa mídia social, também foi fundamental para as investigações, devido à sua proeminência como polimídia na maioria dos campos de pesquisa. A noção de polimídia (polymedia) adverte que não conseguimos entender uma plataforma midiática de forma isolada, devendo percebê-la sempre como rela- 
tiva às outras mídias. Por meio dessa noção, os trabalhos compreenderam que a distinção entre os ambientes digitais também significava a distinção entre as pessoas.

O modo como essa rede social converge tanto sobre as demais ambiências digitais quanto sobre as práticas de consumo foi analisado em relação às materialidades e linguagens digitais que impactavam os significados da vida social. Para os blogueiros de "O Catequista", conforme Flores da Rosa (2018), os vários sites sobre o catolicismo na internet apresentavam boas reflexões, mas não atingiam seus objetivos por utilizar uma linguagem considerada por eles "católica demais". Para realizar essa tradução, os blogueiros aproximaram os conteúdos que produziam das linguagens "características" da mídia social, demarcadas pelo uso de coloquialismos, fórmulas rápidas, humoradas e miméticas. A atenção às materialidades permitiu a Pavanello (20I9) perceber que as mães mantinham o mesmo tipo de zelo entre os perfis na rede social e os bens materiais mais significativos dos(as) filhos(as) perdidos(as), como algumas roupas, ursinhos de pelúcia, violão etc. A preservação da memória digital materializava não apenas a saudade, mas a corporificação e a presença deles(as) (Miller, 2013).

Flores da Rosa (20I8) aponta ainda o impacto da circulação de conteúdos nas práticas cotidianas de vivência da fé por meio do combate às transformações dos rituais e do zelo litúrgico. Um de seus interlocutores, depois de ler no Facebook sobre esse assunto, passou a considerar desrespeitoso bater palmas e acompanhar com pequenos gestos o ritmo das músicas nas celebrações, entendendo a missa como um rito de sacrifício. França (20I8) conclui que a ausência da SUG 02/20I4 (sobre o fim da isenção fiscal das igrejas) no Facebook diminuiu a possibilidade de o tema ser mais bem aproveitado no Senado, pois a falta de divulgação online implicava menor acesso a informações retidas na sociedade civil e que poderiam colaborar com o debate social mais amplo, além daquele já estabelecido para o andamento da proposta.

Outro dado é a forma como as linguagens próprias da internet implicaram, em vários campos de pesquisa, a consolidação de sistemas de classificação do mundo social. Em Flores da Rosa (2018), a catequese dos blogueiros ganha contornos apologéticos a partir do apontamento de "erros" doutrinários e morais das outras crenças e do próprio catolicismo progressista. Expressões como "Católico \#FAIL", "Crente \#FAIL" e "Fantasminha \#FAIL" indicavam, respectivamente, as "falhas" na doutrina de católicos, evangélicos e espíritas. Essas críticas, ao ser compartilhadas no Facebook, acabavam gerando atritos, disputas e discursos intolerantes tanto por católicos quanto por membros dessas religiões, que se consideravam desrespeitados. Em Machado (20I9), a classificação dos comportamentos dos clientes de acordo com o tipo de carro que dirigiam e que apareciam nas fotos do Facebook permitia às interlocutoras realizar uma triagem da clientela. Quanto melhor o carro, melhores as condições de realiza- 
ção do programa e mais alto o pagamento (o que nem sempre acontecia de fato). Da mesma forma, elas compartilhavam denúncias entre si, nas conversas privadas, de perfis de homens bagaceiros, caloteiros e fakes e, de modo público, a todas as pessoas da rede, quando o problema passava dos limites toleráveis. Igualmente importante foi a publicação de How the world changed social media (Miller et al., 20I6), que permitiu às pesquisas comparar seus dados de campo com os resultados das pesquisas em outros países. Além disso, a noção de "sociabilidade escalonável" (scalable sociality), desenvolvida na obra, pontuou a importância de observar as variações entre o tamanho do alcance das interações e os graus de extensão das mídias sociais. De modo geral, para a maioria das pesquisas nas culturas juvenis, o estabelecimento do uso de aplicativos como Tinder e Instagram servia como fronteira para as amizades serem aceitas no Facebook. Somente após a estruturação de laços de confiabilidade nesses ambientes é que os convites mudavam para plataformas consideradas mais pessoais. Em função disso, Trindade (20I8) entendeu como determinadas performances já eram esperadas ou não em cada ambiente. Uma de suas interlocutoras se sentia pressionada a mandar nudes (o que não era uma vontade dela), o que causou o fim do relacionamento que começou no Tinder e migrou para o Whatsapp. Para alguns participantes, a primeira interação no Tinder representa o primeiro passo para a estruturação de um laço com intuito sexual. Posteriormente, as conversações migravam para plataformas como o Whatsapp, o que significava maior intimidade nas conversações e liberdade para que elas assumissem um rumo sexualizado, mediante o envio de nudes e sexting.

Para Tondo (20I6), essa relação implicava não apenas o fato de os jovens continuamente esconderem dos pais e mães determinados conteúdos ou mesmo aplicativos específicos, principalmente os de namoro, ou de moralizarem seus pais e mães quando eram esses(as) que publicavam algum conteúdo considerado inadequado ou vergonhoso, como piadas ou qualquer outro conteúdo alusivo à vida sexual dos(as) adultos(as). Da mesma forma, para Kuntz (20I8), pais e mães, temendo cenários hipotéticos de violência, se preocupavam por sentir que não podiam controlar a circulação dos vídeos das crianças e, para isso, desenvolviam ações protetivas, como desativar os comentários nos vídeos.

Flores da Rosa (20I8) descreve transformações das relações dos leigos com a institucionalidade da religião quando um dos blogueiros foi credenciado à sala de imprensa do Vaticano, colocando a atuação de "O Catequista" em destaque no cenário internacional. Pela primeira vez, o Vaticano concedeu esse tipo de credencial para um não residente de Roma. Um leigo ocupar uma credencial geralmente dada a jornalistas e profissionais religiosos sinaliza como as instituições suportam e resolvem, dentro de suas principais lógicas, as novas formas de atuação articuladas pelo uso da internet. Menezes (2017) também demonstra essa relação conflitiva, apontando como os(as) dançarinos(as) 
do grupo negociam e adentram os circuitos das mídias tradicionais a partir da valorização de estratégias de publicidade e autocomunicação, garantindo acordos e patrocínios com marcas reconhecidas que projetam mais visibilidade ao grupo.

O sistema de fãs e a utilização de um marketing eficiente nas redes sociais, ainda que tenham possibilitado, por exemplo, que uma das dançarinas se tornasse personagem em séries televisivas e embaixadora de marcas de cosméticos e vestuário, não apagaram as contradições da cultura hegemônica. As políticas editoriais da maioria dos veículos definiam os limites e os enquadramentos permitidos ao grupo. É o caso da revista Elle, de março de 20I5, em comemoração ao aniversário da cidade do Rio de Janeiro. O editorial de moda, ainda que "celebre a diversidade" das culturas cariocas, manteve uma dicotomia entre a retidão e o luxo dos brancos em oposição à sexualidade e simplicidade (pobreza) dos negros. No ensaio fotográfico analisado por Menezes, o centro do enquadramento é ocupado por uma modelo branca, única vestida com requinte, enquanto cinco modelos negros(as) apresentam seus corpos quase desnudos.

As SUGs estudadas por França (20I8) também não estão livres dos poderes institucionais intrínsecos às posições partidárias dos(as) senadores(as). A autora aponta que, quando a temática é de interesse dos políticos, recebe maior atenção e incentivo nas redes sociais, incluindo postagens públicas nos perfis de parlamentares, como no Twitter. Quando os temas podem trazer prejuízos e refletir na perda de votos ou privilégios, acaba recebendo menor ou nenhuma atenção. É o caso da SUG 02/20I4 (pelo fim da imunidade tributária para igrejas no Brasil). A proponente, ao perceber a ineficácia de tentar promover um debate online, pois o tema afetava diretamente os interesses conservadores dos parlamentares da bancada religiosa, passou a desenvolver uma agenda de atuação corpo a corpo no Senado. Por outro lado, a SUG 08/20I4 (pela descriminalização do uso da maconha), apesar de ser considerada polêmica, conseguiu apoio mais amplo nas redes sociais, principalmente por acionar conteúdos que mostravam histórias de pessoas que portavam doenças graves, mas que melhoraram com o uso de medicamentos contendo canabidiol. Se o uso recreativo da maconha encontrava resistência nos comentários, o interesse na saúde pública, principalmente quando envolvia doenças em crianças, conseguia mobilizar retornos de interesse à SUG.

\section{DINÂMICAS E DEMARCAÇÕES NAS MÍDIAS DIGITAIS}

Noções relativas ao tempo, às pessoas e às formas de organização das relações sociais descritas nas pesquisas possibilitam entender como esses elementos organizam as experiências digitais e as formas de interação nos contextos observados. A cultura digital, assim, participa da forma como os grupos dão sentido às suas experiências sociais e singularizam distintas maneiras pelas quais a internet passa a ser compreendida (Miller, 20II; Miller et al., 20I6). Em sua 
tese, Silva (20I0) percebeu que, conforme os celulares adentravam os contextos familiares, as pessoas sentiam que precisavam estar perto do aparelho para não perder nenhuma chamada ou SMS. Pereira (20I7) observou essa mesma continuidade, relacionada, todavia, à necessidade de checar constantemente as redes sociais. Para as interlocutoras de Silva (2010), o celular invocava a necessidade de elas estarem " 24 horas" disponíveis para atender ligações, enquanto as de Pereira, da mesma forma, sentiam que deveriam estar "sempre conectadas", principalmente para atender às necessidades de filhos(as) e maridos e para se sentir atualizadas a respeito da vida social. Se as interlocutoras de Pereira estavam conectadas o dia todo para o cuidado familiar, as da pesquisa de Machado (20I9) também sentiam essa noção de urgência do tempo. Os perfis masculinos agiam como se elas estivessem 24 horas disponíveis ao contato sexual, enviando convites incessantes para transas, pedindo fotos, manifestando "elogios" descabidos incansavelmente ou ainda, quando frustradas as tratativas de consumação sexual, avisando que estavam se masturbando com o conteúdo das conversas.

Pavanello (2019) também percebeu como o consumo do Facebook estabelecia uma relação direta entre as mães e a demarcação do tempo da tragédia. Além das publicações sobre amor, valor das amizades, luto e mensagens de protesto e denúncia da impunidade, outro importante uso era o compartilhamento de publicações referentes aos meses e anos transcorridos desde o incêndio. Para elas, o Facebook se transforma em um calendário público de atualização da saudade. O sistema automatizado de "lembranças", que reapresenta na timeline do(a) usuário(a) postagens antigas, também interferia na produção social do afeto, surpreendendo ou emocionando as mães e impactando o gerenciamento cotidiano das emoções.

As pesquisas observam também que as interações com a modalidade "amigo" do Facebook não implicavam necessariamente intimidade ou proximidade. Essas interações geralmente estavam concentradas em modalidades que se encaixam em "outras", no sentido de que elas não configuram relações necessariamente mantidas com pessoas próximas ou conhecidas (Spyer, 20I8; Miller \& Venkatraman, 20I8). Esse deslocamento reconfigura tanto os entendimentos sobre a categoria conceitual "amizade" quanto a noção de pessoa e comportamentos que se articulam nas redes.

Não raras vezes os trabalhos de campo, especialmente sobre as culturas juvenis, pontuaram modalidades de insultos, brigas, ameaças e agressões que não eram apenas admitidos, mas negociados dentro do que cada grupo entende por "amizade de Facebook" e daquilo que é esperado individualmente pelas pessoas conectadas à rede. Interações desse tipo podiam ser percebidas nos aplicativos de conversação, como WhatsApp ou Messenger, ou nos espaços de conversa privada, como as dm (direct message) do Instagram. Para muitos(as) dos(as) interlocutores(as), esses espaços são os principais lugares onde se pode 
conhecer verdadeiramente alguém. Como o perfil na rede social é considerado um lugar de formulação pública da imagem, é nas conversas privadas que as pessoas se dão mais a conhecer, sem tantas amarras sociais.

As publicações e interações públicas permitem maior atuação com atores sociais não muito próximos ou mesmo desconhecidos, ou que tenham algum tipo de interesse, ainda que momentâneo. Isso vale tanto para curtidas (likes) em fotos, que podem independer da proximidade, quanto para marcações e interações mais amplas do que a núcleos sociais específicos. Nesse contexto, a autoapresentação é uma característica fundamental da noção de pessoa elaborada nas redes, que precisa angariar reconhecimento entre aquilo que é postado e o que se sente em relação à pessoa que posta. Por meio da noção de máscara social (Miller, 20I I) - diálogo que se estabelece com os conceitos de "palco", "equipe" ou "fachada social", ou seja, múltiplos arranjos no campo das interações (Goffman, 2009) -, trabalhos como os de Pereira (20I7), Trindade (20I8) e Machado (2019) conseguiram entender contextos digitais em que interessava mais o trabalho de enunciação, ou seja, os esforços para dizer e mostrar do que efetivamente aquilo que se mostrava.

Pereira (2017) identificou esse processo em uma de suas interlocutoras, uma manicure, que se apresentava no Tinder como "doutora", vestindo jaleco branco para se passar por médica. Uma amiga havia ajudado a editar a foto, "diminuindo a papada", as manchas e o tamanho do rosto. Essa mentira, que ela usava mais para se divertir, demonstra uma separação entre sua apresentação nesse aplicativo específico com o perfil do Facebook, em que todos os dados estavam indexados como os mais próximos "à sua vida real". As provocações entre os jovens que não tinham a mesma popularidade nos likes por não terem fotos do corpo sarado, no campo de Trindade, e as fofocas sobre as infidelidades conjugais e falsas juras de amor declaradas no Facebook, na pesquisa de Machado, mostram não apenas como as reputações são projetadas e vão circulando, mas os valores sociais de quem interage com esse tipo de conteúdo.

Já França (20I8) percebeu como a atuação dos proponentes das SUGs implicava seu reconhecimento como ativistas do tema, incluindo as pessoas adicionadas às redes sociais em um sistema de ajuda e reciprocidade. Em um vídeo postado, o interlocutor responsável pela SUG 08/20I4 performa fumando maconha e fazendo explicações sobre o projeto. Ao pedir votos à sugestão, ele ensina as pessoas a ligar para o Alô Senado (canal de comunicação pública) para manifestar apoio ao projeto. A fim de demonstrar como é fácil votar, o rapaz deixa o áudio do telefone no viva-voz e ensina como qualquer pessoa também pode atuar.

A ambiguidade da noção de pessoa se expressa nas mídias digitais da mesma forma com que as relações como parentesco, parentalidades, filiações e associativismos são negociados, flexibilizados ou reforçados, enquanto es truturas concretas do mundo social (Miller \& Madianou, 20I2; Miller \& Venkatraman, 20I8, Miller et al., 20I6). Na pesquisa de Paz (20I9), a organização por 
"patentes" demonstra como os cargos e méritos eram atribuídos aos(às) membros(as) a fim de promover seleções para as diferentes atividades, como o socorro nas crises suicidas ou o mapeio e hackeio de explanadores (quem divulga fotos íntimas das meninas). Dessa forma:

Cada patente tem sua missão que são práticas secretas, entre elas está a nomeada por Forasteiro, que é o menor nível de patente dos membros. São os que estão chegando à comunidade e conhecendo como ela funciona. Também entre os cargos ocupados pelos membros estão os cargos ocultos. São eles: Guarda: Mais velho, Anjos, Deusa Kaneki e Deus Kaneki; Zero, e Rainha da corte. A Guarda são membros que detêm poder maior na comunidade, já com um grau de conhecimentos avançado (Paz, 20I9: II4).

As obrigações e continuidades do parentesco são demonstradas por Pavanello (20I9) tendo em vista que as mães seguem cuidando dos(as) filhos(as) perdidos(as). Uma delas desativou a conta da filha no Twitter depois que pessoas utilizaram uma frase escrita pela jovem na noite da tragédia para espalhar teorias conspiratórias. Essa mãe mantém o perfil da jovem no Facebook "em memória" (quando o perfil fica em funcionamento após a morte do(a) usuário(a) como um espaço recordação), para que os(as) amigos(as) da rede se sintam conectados(as) a ele(ela). A publicação de fotografias, no entanto, não ocorre de forma irrefletida. As mães liberam fotos somente a familiares e amigos(as), pois temem encontrar esse material sendo desrespeitado em sites ou grupos que as acusam de "não deixar a cidade voltar a ser feliz". Kuntz (20I8) percebe como as relações de parentesco redefinem a preocupação dos pais frente a conteúdos considerados danosos à infância e como o YouTube reorganiza a reunião das famílias, circunstância que difere, por exemplo, de assistir à televisão, considerado um ato mais solitário da criança.

Machado (2019) percebeu que as relações de parentesco que se desenvolvem entre as trans eram anteriores a suas inscrições nas mídias digitais e envolviam formas práticas de sobrevivência, uma vez que, ao assumir suas transidentidades, elas eram expulsas de casa, abandonavam a escola e não encontravam trabalho a não ser na prostituição. Com isso, as amizades no Facebook descrevem relações sociais por vezes mais efetivas do que o parentesco consanguíneo. Elas se organizavam como irmãs, filhas, mães, avós, tias (do território material e simbólico que é "se assumir" e "enfrentar a quadra"). A divisão entre casas, famílias e gerações de novas meninas que já eram mães ou tias, em questão de dias ou semanas, a depender da chegada das mais novas à quadra (lugar da prostituição), estabelece as formas desses relacionamentos nas interações digitais. O Facebook disponibiliza, em uma seção "sobre" o usuário, espaço para indexar os perfis de familiares. Nessa seção, o parentesco pela vida da noite era fixado e tornado público. O mesmo acontece para as linhas entre os(as) orixás, que assumem a cabeça daqueles(as) que praticam as religiões de origem africana e que passam a ser assumidos(as) de forma pública nos perfis na rede. 


\section{CONSIDERAÇÕES FINAIS}

Com a análise, demonstramos como as pesquisas do GP Consumo e Culturas Digitais têm realizado uma costura interdisciplinar entre o campo da comunicação e o da antropologia, seja pelo caráter etnográfico das pesquisas analisadas ou dos diálogos com o campo da antropologia do consumo e da antropologia digital e que se alinham às perspectivas teórico-metodológicas de Miller. Para tanto, descrevemos alguns elementos que participam das práticas de consumo e elaboração dos gêneros culturais implicados nos contextos de pesquisa analisados. O estudo do consumo das mídias sociais e das tecnologias digitais, tal como o compreendemos, permite perceber como as pessoas interpretam e dão sentido a suas próprias interações, sendo interpeladas por valores, percepções, moralidades e capitais próprios de que dispõem, pelas configurações da infraestrutura tecnológica, bem como pelas circunstâncias de tempo e espaço em que se encontram. Com isso, demonstramos uma pluralidade de elementos que nos ajudam a compreender como a tecnologia digital participa da vida social e a configura, atuando tanto para a manutenção das normatividades sociais existentes quanto na proposição de agências cotidianas e formas de resistência.

Os gêneros culturais, como usos específicos da cultura material por indivíduos ou grupos, elaboram-se na experiência vivida e nos contextos particulares e cotidianos em que as pessoas utilizam as tecnologias digitais. Essa perspectiva implica entender que os usos das mídias sociais são relacionais, tanto às práticas e aos contextos observados quanto às formas de que dispomos para observar, ou seja, como o trabalho de campo frente a esses contextos vai sendo construído. Nas pesquisas analisadas, esse aspecto está relacionado aos desafios metodológicos, às estratégias para acesso às experiências digitais, à permanência junto a interlocutores(as) e ao reposicionamento dos imponderáveis que podem se desdobrar em cenários tanto online quanto off-line. Tondo (20I6) e Trindade (20I8) desenvolveram atividades pedagógicas nas escolas, utilizando esses espaços para a observação empírica. Além disso, mais de uma vez, afirmaram que se envolveram nas "tretas" (confusões) de seus(suas) interlocutores(as), atuando como mediadores, precisando ponderar até que ponto "tomar uma posição" causaria impasses e problemas para o desenvolvimento das pesquisas.

Nos trabalhos com mulheres, Pereira (20I7) e Machado (20I9) entenderam que as mídias digitais os aproximavam das interlocutoras em momentos que o contato físico era impossível. Antes dessa aproximação, partilhavam de um sentimento de insegurança (de importunar, de as interlocutoras "simplesmente" desistirem da pesquisa), o que implicava estratégias para manter as interações. Participar da vida social off-line ajudava a manter esses vínculos, mas eles não podiam ser tomados de forma apriorística. Por isso, revelam que se transformaram em confidentes (principalmente amorosos), tendo que, para isso, dividir suas próprias intimidades. 
Machado (2019) percebeu ainda que o trabalho de campo seria entrecortado de acordo com as temporadas de suas interlocutoras e optou por utilizar as mensagens em áudio do WhatsApp, mas só depois de perceber que o cotidiano possuía uma organização própria. De manhã, elas voltavam cansadas da quadra e dormiam. Interagiam melhor à tardinha (enquanto se arrumavam para sair) ou à noite, no intervalo entre um atendimento e outro. Suas interlocutoras também souberam utilizar dessa ferramenta de acordo com suas necessidades, como quando estavam em alguma situação de risco e pediam para que ele ficasse conectado com elas, para demonstrar a alguém (em geral algum homem inoportuno ou perigoso) que elas não estavam sozinhas.

Kuntz (20I8), por sua vez, aponta que as crianças estavam mais abertas a conversar com ela na internet do que presencialmente, quando pareciam mais envergonhadas. Ela indaga, sobre essas conversas, se as respostas monossilábicas que recebia poderiam indicar um aparente desinteresse ou, pelo contrário, uma característica própria da linguagem infantil - não exigindo delas vasto domínio da linguagem escrita ou grandes explicações de suas ações na internet. A imersão de Paz (20I9) implicou sua própria transformação como pessoa para o grupo. Inicialmente considerada uma forasteira (quem sabe pouco sobre o grupo), ela se candidatou à patente de diário (pessoa que se comporta como um "livro aberto" para que a "caneta", o(a) jovem que está precisando de ajuda, "escreva" nele). A partir disso, recebeu de uma interlocutora de I7 anos um treinamento para atuação terapêutica, que implicava seguir um conjunto de I r regras e preencher modelos de "relatórios diários" e "prontuários" apresentando as características depressivas e os quadros de melhora que precisava enviar regularmente aos seus superiores.

Com esses exemplos queremos demonstrar que a inscrição dos(as) pesquisadores(as) em campo implica formas específicas de atuação - tanto em relação às mídias quanto a interlocutores(as) - tendo como referente as principais dinâmicas e características de cada contexto. O modo como essa atuação vai sendo construída implica diretamente como cada realidade social vai sendo interpretada. Assim, temos destacado a importância de situar nossos próprios usos e apropriações, o que permite inquirir as configurações metodológicas e as estratégias que conformam o exercício da pesquisa.

Essa postura reflexiva se assenta na percepção crítica da antropologia de Miller, de que, por meio dos estudos da cultura material e das tecnologias digitais, é possível pensar as transformações tanto da humanidade quanto da própria produção de conhecimento, pois "parece razoável, portanto, também usar a antropologia digital para desenvolver debates sobre o que a humanidade está se tornando e também o que a antropologia está se tornando" (Miller, 20I8, tradução nossa). Não refletir sobre nossas próprias práticas é ignorar o movimento situacional, dialético e mediado das experiências que 
desejamos compreender e, por conseguinte, perder de vista um dos maiores ensinamentos que Daniel Miller nos deu, de que o digital é humano.

Recebido em I3/5/2020 | Revisto em 30/8/2020 | Aprovado em 28/9/2020

Sandra Rúbia da Silva é doutora em antropologia social pela Universidade Federal de Santa Catarina, com período sanduíche no University College London, com supervisão de Daniel Miller. Mestra em comunicação e informação pela Universidade Federal do Rio Grande do Sul e bacharela em comunicação social publicidade e propaganda pela Universidade Regional de Blumenau. É docente do Departamento de Ciências da Comunicação e do Programa de Pós-Graduação em Comunicação da Universidade Federal de Santa Maria e pesquisadora-líder do GP Consumo e Culturas Digitais (UFSM/ CNPq). Seus atuais interesses de pesquisa e áreas de atuação incluem teorias do consumo, cultura material, culturas digitais e práticas de consumo da internet para a inclusão social.

Alisson Machado é doutor e mestre em comunicação pelo Programa de PósGraduação em Comunicação da Universidade Federal de Santa Maria e bacharel em comunicação social, habilitação em jornalismo, pela mesma instituição. Membro do GP Consumo e Culturas Digitais (UFSM/CNPq). Seus atuais interesses de pesquisa e áreas de atuação incluem as perspectivas qualitativas de investigação; antropologia e consumo das mídias; e mídia, relações entre gênero, corpo e sexualidade. 


\section{NOTAS}

I Vinculado ao Programa de Pós-Graduação em Comunicação da Universidade Federal de Santa Maria.

2 No texto, essas expressões são utilizadas como sinônimos. Noção advinda de Certeau (20I4), de que os usos possibilitam consumos combinatórios, arte de utilizar que circunscreve as práticas do consumo na vida cotidiana. A elas se soma com mesmo significado a expressão "gêneros culturais" tomada de Miller (2013; Miller et. al., 2016) para sinalizar práticas particulares de consumo das tecnologias. O consumo é entendido como um fenômeno social, simbólico e cultural (Miller, I987; Sahlins, 2003; Douglas \& Isherwood, 2004; Barbosa \& Campbell, 2006), e os contornos e enfoques midiáticos estão entremeados nessas práticas.

3 Aproximações entre o campo da comunicação e a antropologia podem ser encontradas, entre outros, em trabalhos como os de Travancas e Farias (2003) e Lago (2008).

4 Os trabalhos, ao refletir o consumo por camadas populares, criticam especialmente as políticas da carência material (Sarti; 20II; Rocha \& Barros, 2009). Com isso, percebem não apenas os esquemas de distinção entre grupos (Bourdieu, 2007), mas também o impacto, a ascensão e a participação social das camadas populares pelo consumo (Slater, 2002; Silva, 2008).

\section{REFERÊNCIAS BIBLIOGRÁFICAS}

Barbosa, Livia. (2003). Sociedade do consumo. Rio de Janeiro: Zahar.

Barbosa, Livia \& Campbell, Collin (orgs.). (2006). Cultura, consumo e identidade. Rio de Janeiro: Editora FGV. Barbosa, Livia \& Gomes, Laura Graziela (2004). Apresentação ao dossiê sobre antropologia do consumo. Antropolítica, Niterói, I7.

Barros, Carla. (2007). Trocas, hierarquias e mediação: as dimensões culturais do consumo em um grupo de empregadas domésticas. Tese de Doutorado. PPGA/Universidade Federal do Rio de Janeiro. 
Bourdieu, Pierre. (2007). A distinção: crítica social do julgamento. São Paulo/Porto Alegre: Edusp/Zouk.

Brites, Jurema \& Motta, Flávia de Mattos (orgs.). (2017). Etnografia, o espírito da antropologia. Tecendo linhagens: homenagem a Claudia Fonseca. Santa Cruz do Sul: Edunisc.

Campanella, Bruno \& Barros, Carla. (2016). Etnografia e consumo midiático: novas tendências e desafios metodológicos. Rio de Janeiro: E-papers.

Cardoso de Oliveira, Roberto. (2006). A antropologia e a "crise" dos modelos explicativos. In: O trabalho do antropólogo. São Paulo: Editora Unesp, p. 53-7I.

Certeau, Michel de. (20I4). A invenção do cotidiano: artes do fazer. Petrópolis: Vozes.

Clifford, James. (1998). A experiência etnográfica: antropologia e literatura no século XXI. Rio de Janeiro: Editora UFRJ.

DaMatta, Roberto. (20I0). Relativizando: uma introdução à antropologia. Rio de Janeiro: Rocco.

Douglas, Mary \& Isherwood, Baron. (2004). O mundo dos bens: para uma antropologia do consumo. Rio de Janeiro: Editora UFRJ.

Flores da Rosa, Ana Cássia. (2018). A internet dos leigos: catolicismo midiático e práticas de consumo como experiência vivida. Tese de Doutorado. Poscom/Universidade Federal de Santa Maria.

Fonseca, Claudia. (I999). Quando cada caso NÃO é um caso. Pesquisa etnográfica e educação. Revista Brasileira de Educação, ıo, p. 58-78.

França, Jonária. (20I8). Participação política na timeline: o Facebook como arena política para sugestões legislativas apresentadas no E-cidadania. Tese de Doutorado. Poscom/Universidade Federal de Santa Maria.

França, Vera. (200I). Paradigmas da comunicação: conhecer o quê? Ciberlegenda, 5, p. I-I9.

Geertz, Clifford. (2013). "Do ponto de vista dos nativos": a natureza do entendimento etnográfico. In: O saber local: novos ensaios em antropologia interpretativa. Rio de Janeiro: Vozes, p. 60-74.

Geertz, Clifford. (2012). A interpretação das culturas. Rio de Janeiro: LTC. 
Gil, Antonio Carlos. (I999). Métodos e técnicas de pesquisa social. São Paulo: Atlas.

Goffman, Erving. (2009). A representação do eu na vida cotidiana. Petrópolis: Vozes.

Grossi, Miriam Pillar. (2004). A dor da tese. Ilha, 6, p. 22 I232.

Hine, Christine. (20I5). Ethnography for the internet. Embedded, embodied and everyday. London: Bloommsbury.

Hine, Christine. (2000). Virtual ethnography. London: Sage Books.

Horst, Heather \& Miller, Daniel. (2012). Digital anthropology. London: Berg.

Horst, Heather \& Miller, Daniel. (2006). The cell phone: an anthropology of communication. Oxford: Berg.

Horst, Heather et al. (20I2). Rethinking ethnography: an introduction. Media International Australia, Incorporating Culture \& Policy, I45, p. 86-93.

Kuntz, Fárida Monireh Rabuske. (2018). Crianças no Youtube: um estudo etnográfico sobre as infâncias e suas estratégias de relacionamento nas mídias digitais. Dissertação de Mestrado. Poscom/Universidade Federal de Santa Maria.

Lago, Cláudia. (2008). Antropologia e jornalismo: uma questão de método. In: Lago, Cláudia \& Benetti, Marcia (orgs.). Metodologia da pesquisa em jornalismo. Petrópolis : Vozes, p. 48-66.

Leitão, Débora Krische \& Gomes, Laura Graziela. (20I7). Etnografia em ambientes digitais: perambulações, acompanhamentos e imersões. Antropolítica, 42, p. 4I-65.

Leitão, Débora Krische et al. (2006). Antropologia e consumo: diálogos entre Brasil e Argentina. Porto Alegre: AGE.

Machado, Alisson. (20I9). Toda trabalhada na Wi-fi: cotidiano travesti em trajetórias digitais. Tese de Doutorado. Poscom/Universidade Federal de Santa Maria.

Machado, Monica. (20I5). Daniel Miller: "A antropologia digital é o melhor caminho para entender a sociedade moderna". Zcultural, Io. Disponível em <https://bit. ly/3j8YJnh>. Acesso em 24 ago. 2020. 
Machado, Monica (2010). Consumo e politização: discurso publicitário e novas formas de engajamento juvenil. Tese de Doutorado. PPGCC/Universidade Federal do Rio de Janeiro.

Martín-Barbero, Jesús. (2009). Uma aventura epistemológica. Matrizes, 2, p. I43-162.

Martineli, Fernanda. (20II). Pirataria SA. Circulação de bens, pessoas e informação nas práticas de consumo. Tese de Doutorado. PPGCC/Universidade Federal do Rio de Janeiro.

Mauss, Marcel. (2003). Sociologia e antropologia. São Paulo: Cosac Naify.

Menezes, Darciele Paula Marques. (2017). No ritmo do passinho: deslocamentos midiáticos e estetização cotidiana do grupo Dream Team do Passinho. Tese de Doutorado. Poscom/ Universidade Federal de Santa Maria.

Miller, Daniel. (2018). Digital anthropology. In: Stein, Felix et al. (eds.). The Cambridge Encyclopedia of Anthropology. Disponível em <https://www.anthroencyclopedia.com/ entry/digital-anthropology>. Acesso em 24 ago. 2020.

Miller, Daniel. (20I3). Trecos, troços e coisas: estudos antropológicos sobre a cultura material. Rio de Janeiro: Zahar.

Miller, Daniel. (20II). Tales from Facebook. Boston: Polity.

Miller, Daniel. (2007). Consumo como cultura material. Horizontes Antropológicos, I3, p. 33-63.

Miller, Daniel. (1987). Material culture and mass consumption. Oxford: Basil Blackwell.

Miller, Daniel \& Madianou, Mirca. (20I2). Deve-se aceitar uma solicitação de amizade da própria mãe? E outros dilemas filipinos. In: Rial, Carmen; Silva, Sandra Rúbia da; Souza, Angela Maria. Consumo e cultura material: perspectivas etnográficas. Florianópolis: Ed. da UFSC, p. 23-48.

Miller, Daniel \& Slater, Don. (2000). The internet: an ethnographic approach. New York: Oxford.

Miller, Daniel \& Venkatraman, Shriram. (2018). Facebook Interactions: An Ethnographic Perspective. Social Media + Society, 4/3, P. I-II.

Miller, Daniel et al. (2016). How the world changed social media. London: UCL Press.

Mizrahi, Mylene. (20I4). A estética do funk carioca: criação e conectividade em Mr. Catra. Rio de Janeiro: 7 Letras. 
Oliven, Ruben George \& Pinheiro-Machado, Rossana. (2007). Apresentação. Horizontes Antropológicos, Porto Alegre, I3/28.

Pavanello, Alice Bianchini. (2019). Práticas de consumo das redes sociais por mães de vítimas do incêndio na Boate Kiss: a criação de experiências no cotidiano. Dissertação de Mestrado. Poscom/Universidade Federal de Santa Maria.

Paz, Aline Amaral. (20I9). O suicídio em torno da vida e da morte: uma etnografia do consumo do Facebook por jovens. Dissertação de Mestrado. Poscom/Universidade Federal de Santa Maria.

Peirano, Mariza. (20I4). Etnografia não é método. Horizontes Antropológicos, 20, p. 377-39r.

Peirano, Mariza. (1994). A favor da etnografia. Anuário Antropológico, 92, p.I97- 223.

Pereira, Camila Rodrigues. (20I7). "Em um relacionamento sério com o celular": uma etnografia das práticas de consumo de smartphones por mulheres. Dissertação de Mestrado. Poscom/Universidade Federal de Santa Maria.

Pinheiro-Machado, Rossana. (2009). Made in China. Produção e circulação de mercadorias no circuito China-ParaguaiBrasil. Tese de Doutorado. PPGAS/Universidade Federal do Rio Grande do Sul.

Rocha, Everardo \& Barros, Carla. (2009). Lógica de consumo em um grupo de camadas populares: uma visão antropológica de significados culturais. In: Rocha, Angela \& Silva, Jorge Ferreira (orgs.). Consumo na base da pirâmide: estudos brasileiros. Rio de Janeiro: Mauad X.

Sahlins, Marshall. (2003). Cultura e razão prática. Rio de Janeiro: Jorge Zahar Ed.

Salvador, Ângelo Domingos. (I986). Métodos e técnicas de pesquisa bibliográfica. Porto Alegre: Sulina.

Sarti, Cynthia Andersen. (20I I). A família como espelho: um estudo sobre a moral dos pobres. São Paulo: Cortez.

Sheppard, Emily. (20I2). Anthropology goes online: an ethnography of online interactions. Ethnografhic Encounters, I/2, p. 50-6I.

Silva, Sandra Rúbia da. (2012a). Performances de masculi- 
nidade, práticas de subversão: o consumo de telefones celulares entre jovens de camadas populares. Comunicação, Mídia e Consumo, 9, p. 6I-82.

Silva, Sandra Rúbia. (2012b). "Com o celular é 24 horas no ar": sobre relações de gênero e apropriação de tecnologias móveis em camadas populares. Intexto, 27, p. II6-I30.

Silva, Sandra Rúbia da. (20Io). Estar no tempo, estar no mundo: a vida social dos telefones celulares em um grupo popular. Tese de Doutorado. PPGAS/Universidade Federal de Santa Catarina.

Silva, Sandra Rúbia da. (2008). Vivendo com celulares: identidades, corpo e sociabilidade nas culturas urbanas. In: Borelli, Silvia Helena Simões \& Freire Filho, João. (orgs.). Culturas juvenis no século XXI. São Paulo: Educ, p. 3II-33I.

Slater, Don. (2002). Cultura de consumo \& modernidade. São Paulo: Nobel.

Spyer, Juliano. (2018). Mídias sociais no Brasil emergente: Como a internet afeta a mobilidade social. London: UCL Press.

Strathern, Ann Marilyn. (20I4). O efeito etnográfico e outros ensaios. São Paulo: Cosac Naify.

Tondo, Romulo Oliveira. (2016). Celulares, conexões e afetos: a sociabilidade e o consumo de smartphones entre jovens de comunidade popular. Dissertação de Mestrado. Poscom/Universidade Federal de Santa Maria.

Travancas, Isabel \& Farias, Patrícia. (2003). Antropologia e comunicação. Rio de Janeiro: Garamond.

Trindade, Thiago Álvares. (2018). "A gente se ama e se odeia ao mesmo tempo": uma etnografia do consumo de smartphones em circuitos de sociabilidade de jovens de camadas populares. Dissertação de Mestrado. Poscom/Universidade Federal de Santa Maria.

Velho, Gilberto. (2013). Um antropólogo na cidade: ensaios de antropologia urbana. Rio de Janeiro: Zahar. 


\section{DIÁLOGOS COM DANIEL MILLER NO CAMPO DA COMUNICAÇÃO: REFLEXÕES A PARTIR DAS PESOUISAS DO GP CONSUMO E CULTURAS DIGITAIS}

Resumo

O artigo reflete as práticas de investigação do grupo de pesquisa Consumo e Culturas Digitais (UFSM/CNPq) tendo em vista o legado teórico de Daniel Miller a respeito do consumo e da cultura material em interface com os estudos do campo da comunicação e, em especial, das culturas digitais. Mediante a apreciação crítica de quatro teses e seis dissertações, demonstramos como temos realizado diálogos com a antropologia digital por meio da tessitura de diferentes pesquisas de campo que animam e propõem desafios à pesquisa empírica. Nossa filiação à linhagem etnográfica de Miller nos faz perseguir o argumento de que as práticas cotidianas de consumo da internet, das mídias sociais e de dispositivos móveis podem ser entendidas enquanto gêneros culturais que se elaboram na experiência vivida e nos contextos particulares em que as mídias digitais são utilizadas.

\section{DIALOGUES WITH DANIEL MILLER IN THE COMMUNICATION FIELD: REFLECTIONS FROM THE RESEARCH OF CONSUMPTION AND DIGITAL CULTURES RESEARCH GROUP} terface with studies in the field of communication and in particular of digital cultures. Through the critical appraisal of four theses and six dissertations, it demonstrates how we have been working with digital anthropology through the interlacement of different field researches that animate and pose challenges to empirical research. Our affiliation with Miller's ethnographic lineage makes us pursue the argument that it is possible to understand the everyday consumption practices of the internet, social media and mobile devices as cultural genres elaborated in the lived experience and in the particular contexts in which digital media are used.
Palavras-chave

Consumo; cultura material; etnografia; internet; mídias digitais.
Keywords

Consumption; material culture; ethnography; internet; digital media. 